\title{
Vibration model as a system of coupled oscillators in a direct current electric motor
}

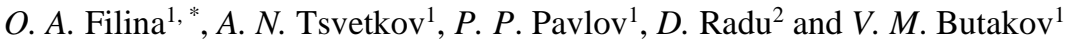 \\ ${ }^{1}$ Kazan State Power Engineering University, Kazan, Russia \\ ${ }^{2}$ University «Stefan cel Mare» of Suceava, Romania
}

\begin{abstract}
This article describes a vibration model connected by individual nodes of a DC motor. The purpose of the article is a mathematical model allowing to predict the work of machines with a depreciation resource and search for ways to increase the information content of assessing the functioning of the rolling stock condition without dismantling them. Currently, the operational reliability of the DC motor is reduced after the development of the service life. Study and evaluation of the vibration effect on the brush-collector node. The main components of the DC motor (bearings, electrical brushes) are unrecoverable. Therefore, any interference with their normal operation leads to premature wear of the entire DC motor. Existing methods for life-extending maintain the operational reliability of a DC motor equal or close to the passport data for several years. This model allows vibration diagnostics without dismantling the DC motor and stopping the rolling stock. The mathematical model describes the oscillations of each node of the DC motor in the direction of movement of the rolling stock, showing the excess of the permissible value. After mathematical processing of the results, a machine reliability model under study is obtained (usually in the form of polynomials) as a function of the needed parameters - the influencing factors. Due to this model, pre-detected defects can save on repairs and maintenance in the future. This model is the basis of software for online diagnostics. The proposed model allows providing an objective use of repair and restoration compositions depending on the current technical condition, which will lead to an increase in the service life of the mechanism and savings in operating costs. On the one hand, extending the operating life of a DC motor should produce an economic effect, and on the other hand, technical measures to maintain operational reliability cause an increase in material costs.
\end{abstract}

\section{Introduction}

The model of vibrations can be represented as a system of connected nodes of which a direct current motor (DC motor) consists, we will call it oscillators. Due to the individual motor elements' masses, stiffness and damping factors for these elements, such as mechanical transverse excitation of the rotating armature, collector, fan, bearings, vibrations of brush holder, poles and column (for example, due to the movement of the object with DC motor) (Fig. 1), in modeling, we can observe the emergence of complex structures that can be described as a superposition of harmonic oscillations called normal oscillations [1-10].

\section{Methods}

Assuming that the displacements during vibrations are directed only vertical, we will have a one-dimensional system of five "particles" with masses $m_{i}(i=1, \ldots$, 5)connected by springs. We assume that the mass of springs is zero, the stiffness coefficients (or elasticities, or force constants) are equal to $k_{i}$, the damping coefficients are $c_{i}$.

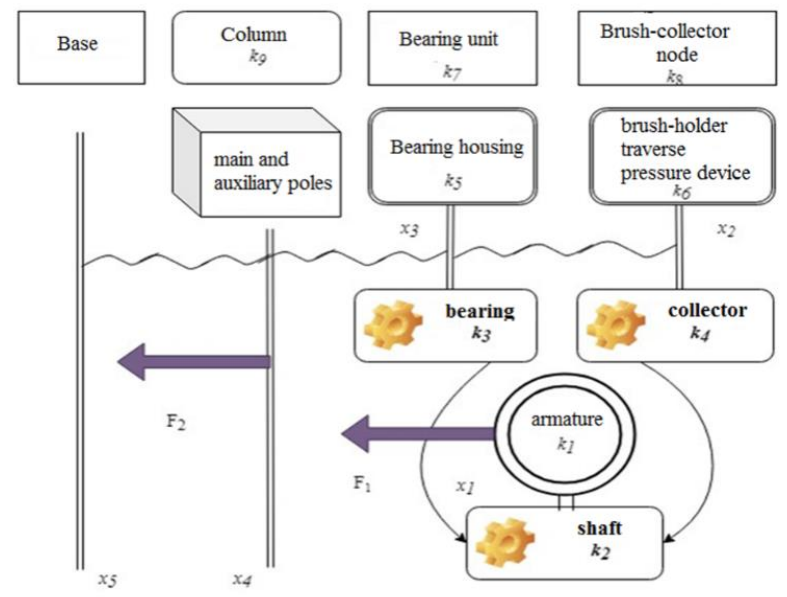

Fig. 1. Model of motor vibration.

Let us denote $x_{i}$ as $i$ mass displacement from the balance position along the displacement axis. The boundary point $x_{5}$ (the base to which the column is attached) will be assumed fixed, which is expressed by the boundary condition $x_{5}=0$. And the displacement of

\footnotetext{
*Corresponding author: olga_yuminova83@mail.ru
} 


$$
\left\{\begin{array}{l}
m_{1} \cdot d_{t}^{2} x_{1}=\frac{k_{1} k_{2} k_{3} k_{4}}{k_{1} k_{2}+k_{2} k_{3}+k_{2} k_{4}+k_{4} k_{1}}\left(x_{1}-x_{2}-x_{3}\right)-\frac{c_{1} c_{2} c_{3} c_{4}}{c_{1} c_{2}+c_{2} c_{3}+c_{2} c_{4}+c_{4} c_{1}}\left(\partial_{t} x_{1}-\partial_{t} x_{2}-\partial_{t} x_{3}\right)+F_{1} \\
m_{2} \cdot d_{t}^{2} x_{2}=\frac{k_{4} k_{6}}{k_{4}+k_{6}}\left(x_{1}-x_{2}\right)-\frac{c_{4} c_{6}}{c_{4}+c_{6}}\left(\partial_{t} x_{2}-\partial_{t} x_{3}\right)+\frac{k_{3} k_{4}}{k_{1} k_{2}+k_{2} k_{3}+k_{2} k_{4}+k_{4} k_{1}}\left(x_{1}-x_{2}-x_{3}\right)- \\
-\frac{c_{1} c_{2} c_{3} c_{4}}{c_{1} c_{2}+c_{2} c_{3}+c_{2} c_{4}+c_{4} c_{1}}\left(\partial_{t} x_{1}-\partial_{t} x_{2}-\partial_{t} x_{3}\right) ; \\
m_{3} \cdot d_{t}^{2} x_{3}=\frac{k_{3} k_{5}}{k_{3}+k_{5}}\left(x_{1}-x_{3}\right)-\frac{c_{3} c_{5}}{c_{3}+c_{5}}\left(\partial_{t} x_{1}-\partial_{t} x_{3}\right)+\frac{k_{4} k_{6}}{k_{4}+k_{6}}\left(x_{1}-x_{2}\right)-\frac{c_{4} c_{6}}{c_{4}+c_{6}}\left(\partial_{t} x_{2}-\partial_{t} x_{3}\right)+ \\
+\frac{k_{1} k_{2} k_{3} k_{4}}{k_{1} k_{2}+k_{2} k_{3}+k_{2} k_{4}+k_{4} k_{1}}\left(x_{1}-x_{2}-x_{3}\right)-\frac{c_{1} c_{2} c_{3} c_{4}}{c_{1} c_{2}+c_{2} c_{3}+c_{2} c_{4}+c_{4} c_{1}}\left(\partial_{t} x_{1}-\partial_{t} x_{2}-\partial_{t} x_{3}\right) \\
m_{4} \cdot d_{t}^{2} x_{4}=-k_{9}\left(x_{4}-x_{1}\right)-c_{9}\left(\partial_{t} x_{4}-\partial_{t} x_{1}\right)+\frac{k_{3} k_{4}}{k_{3}+k_{4}}\left(x_{4}-x_{2}-x_{3}\right)+\frac{c_{3} c_{4}}{c_{3}+c_{4}}\left(\partial_{t} x_{4}-\partial_{t} x_{2}-\partial_{t} x_{3}\right) \\
m_{5} \cdot d_{t}^{2} x_{5}=k_{9}\left(x_{4}-x_{5}\right)+c_{9}\left(\partial_{t} x_{4}-\partial_{t} x_{5}\right)-\frac{k_{7} k_{8}}{k_{7}+k_{8}} x_{4}+\frac{c_{7} c_{8}}{c_{7}+c_{8}} \partial_{t} x_{4}+F_{2}
\end{array}\right.
$$

the column, for example, when an object moves on an unequal surface, will be set by affecting the external force $F_{2}$ of one or another kind. The force $F_{1}$ describes the transverse mechanical excitations of the shaft, armature, collector, bearings and fan in rotating. [11]

The irregularity of the collector should not exceed $0.05 \mathrm{~mm}$; a sinusoidal profile negatively affects the brush-collector node. The future model should include a model of the irregularities of the form.

$$
Z_{4}(t)=A \sin (\omega t) \leq 0.05 \sin (\omega t)
$$

The oscillations behavior of a multi-mass system with elastic constraints will be described by classical mechanics equations. Newton'slawsmustbeused:

$$
F_{1}=-F_{2}, F=m a=m d v(t) / d t
$$

Hooke Law is

$$
F=-k Z(t)
$$

Since the force acting on the $\mathrm{i}$ mass is determined only by compression and tension of the springs connecting with it, the motion equations for each of the masses will have the form (4). Where $k_{c}=0$, the system (1) divides into independent equations and the motion of each mass does not depend on its nodes.

The motion equation (1) describes the longitudinal oscillations, i.e. movement along the system directed from left to right. We can also show that similar equations describe the transverse oscillations of $N$ coupled point masses.

The values of the displacements $x_{1}=x_{2}=x_{3}=x_{4}=$ $x_{5}=0$ correspond to the system balance.

Upperfrequencyisequalto

$$
\omega_{1}=\sqrt{\left(\kappa+2 \kappa_{c}\right) / m}
$$

In this mode, both particles oscillate in antiphase (the displacements are directed in opposite directions).

Movement on the lower frequency

$$
\omega_{2}=(k / m)^{1 / 2}
$$

corresponds to the oscillations of both particles in phase. Noting that in (2), the motion does not depend on $k_{\mathrm{c}}$.

The general motion of such a system is a superposition of both normal oscillations. [12]

1. If $\omega_{1}$ and $\omega_{2}$ are not connected by a simple relation, the resulting displacement is a complex function in time.

2. If the connection is weak, then $\omega_{1} \approx \omega_{2}$ and then the beating are observed in the oscillations of $v_{l}(t)$ and $v_{i}(t)$.

In this case, the elements of the nodes quickly oscillate with an angular frequency

$$
\left(\omega_{1}+\omega_{2}\right) / 2
$$

andamplitude varying sinusoidally with a beating frequency

$$
\left(\omega_{1}-\omega_{2}\right) / 2
$$

The frequency of normal system vibrations consisting of $n$ elements with masses $m$ is determined by the formula:

$$
\omega_{n}=2 \sqrt{\frac{k}{m}} \sin \frac{n \pi}{2(N+1)}
$$

where

$n=1, \ldots, N$ is the oscillation number.

To solve the equation system (1), it is necessary to specify the initial positions of the masses and their initial 


$$
\left\{\begin{array}{l}
d_{t} x_{1}=v_{1} \\
m_{1} \cdot v_{1}=\frac{k_{1} k_{2} k_{3} k_{4}}{k_{1} k_{2}+k_{2} k_{3}+k_{2} k_{4}+k_{4} k_{1}}\left(x_{1}-x_{2}-x_{3}\right)-\frac{c_{1} c_{2} c_{3} c_{4}}{c_{1} c_{2}+c_{2} c_{3}+c_{2} c_{4}+c_{4} c_{1}}\left(v_{1}-v_{2}-v_{3}\right)+F_{1} \\
d_{t} x_{2}=v_{2} \\
m_{2} \cdot v_{2}=\frac{k_{4} k_{6}}{k_{4}+k_{6}}\left(x_{1}-x_{2}\right)-\frac{c_{4} c_{6}}{c_{4}+c_{6}}\left(v_{2}-v_{3}\right)+\frac{k_{1} k_{2} k_{3} k_{4}}{k_{1} k_{2}+k_{2} k_{3}+k_{2} k_{4}+k_{4} k_{1}}\left(x_{1}-x_{2}-x_{3}\right)- \\
-\frac{c_{1} c_{2} c_{3} c_{4}}{c_{1} c_{2}+c_{2} c_{3}+c_{2} c_{4}+c_{4} c_{1}}\left(v_{1}-v_{2}-v_{3}\right) ; \\
d_{t} x_{3}=v_{3} \\
m_{3} \cdot v_{3}=\frac{k_{3} k_{5}}{k_{3}+k_{5}}\left(x_{1}-x_{3}\right)-\frac{c_{3} c_{5}}{c_{3}+c_{5}}\left(v_{1}-v_{3}\right)+\frac{k_{4} k_{6}}{k_{4}+k_{6}}\left(x_{1}-x_{2}\right)-\frac{c_{4} c_{6}}{c_{4}+c_{6}}\left(v_{2}-v_{3}\right)+ \\
+\frac{k_{1} k_{2} k_{3} k_{4}}{k_{1} k_{2}+k_{2} k_{3}+k_{2} k_{4}+k_{4} k_{1}}\left(x_{1}-x_{2}-x_{3}\right)-\frac{c_{1} c_{2} c_{3} c_{4}}{c_{1} c_{2}+c_{2} c_{3}+c_{2} c_{4}+c_{4} c_{1}}\left(v_{1}-v_{2}-v_{3}\right) \\
d_{t} x_{4}=v_{4} \\
m_{4} \cdot \mathrm{Z}_{4}(t) \cdot v_{4}=-k_{9}\left(x_{4}-x_{1}\right)-c_{9}\left(v_{4}-v_{1}\right)+\frac{k_{3} k_{4}}{k_{3}+k_{4}}\left(x_{4}-x_{2}-x_{3}\right)+\frac{c_{3} c_{4}}{c_{3}+c_{4}}\left(v_{4}-v_{2}-v_{3}\right) \\
d_{t} x_{5}=v_{5} \\
m_{5} \cdot v_{5}=k_{9}\left(x_{4}-x_{5}\right)+c_{9}\left(v_{4}-v_{5}\right)-\frac{k_{7} k_{8}}{k_{7}+k_{8}} x_{4}+\frac{c_{7} c_{8}}{c_{7}+c_{8} \partial_{t} x_{4}+F_{2}}
\end{array}\right.
$$

displacement rates, i.e. formulate the initial conditions of the Cauchy problem:

$$
\begin{aligned}
& x_{1}(0), x_{2}(0), x_{3}(0), x_{4}(0), x_{5}(0) \\
& v_{1}(0), v_{2}(0), v_{3}(0), v_{4}(0), v_{5}(0)
\end{aligned}
$$

where $v_{\mathrm{i}}(0)=\left.\partial_{t} x_{i}\right|_{t=0}$, and also determine the forces impacting the system. The force acting on the motor armature, in the simplest case, can be represented as harmonic:

$$
F_{1}=F_{1,0} \cos (\omega t+\varphi)
$$

As for the impact on the motor column, for example, when the whole system moves on an unequal surface, then, in general, since the distribution of inequality is random, the amplitude and frequency of external influence on the column described by $F_{2}$ force are random variables. The impact force can be specified, for example, as a random Gaussian noise:

$$
F_{2}=F_{2,0}(t)_{0} \cos [\omega(t)+\varphi]
$$

where the time-amplitude and frequency will be generated using random number sensors.

Thus, by equalities (4-12), we completely determined the model describing the associated vibrational oscillations of individual motor components, and hence the motor as a whole. In the general case, we cannot analytically solve the constructed model, including a system of non-uniform second-order differential equations, describing the oscillations of a coupled system of elements, taking into account damping and external influences, one of which is random. Individual parts of the solution, for example, in the case of free oscillations in the absence of external influences, can be studied analytically, of course. But the solution to the problem we have set requires the use of statistical approaches to studying the vibration characteristics of such a complex system as a motor. And now the motor model is fully defined, we can begin consideration of the vibration simulation algorithm [13]

Due to irregularities on the side of the collector, the beating frequency lies in a wide range from 750 to 850 $\mathrm{Hz}$, from 150 to $500 \mathrm{~Hz}$ - developing bearing defects, from 200 to $450 \mathrm{~Hz}$ - defects in the motor stator and at the poles.

\section{Simulation algorithm results}

In accordance with the adopted laws and the calculated kinematic equivalent circuit, we can record the balance of mechanical forces for each element separately.

For simulating the dynamic behavior of five coupled masses, a system of five second-order differential equations is first described as a system of first-order differential equations using the natural notation $d_{t} x_{i}=v_{i}$ (13).

The Euler-Cromer algorithm is used in calculating the displacements and velocities of the associated masses $m_{i}(i=1, \ldots, 5)$. For each pair of system equations (5) it will look as: 


$$
\begin{aligned}
& v_{i}^{n+1}=v_{i}^{n}+a_{i}^{n+1} \Delta t, \\
& x_{i}^{n+1}=x_{i}^{n}+v_{i}^{n+1} \Delta t, \\
& t^{n}=t^{0}+n \Delta t, i=1, \ldots, 5
\end{aligned}
$$

where superscripts correspond to the step number in $t$, $a_{i}^{n+1}$ is the right-hand side of the even equation of system (5) for the $i$ mass divided by this mass with superscripts $n$ for $x$ and $v$.

Since the Cauchy problem was initially posed and we identified second-order differential equations, we must also set initial conditions:

$$
\left.x_{i}\right|_{t=0}=x_{i}^{0},\left.\quad v_{i}\right|_{t=0}=v_{i}^{0} ; i=1, \ldots, 5
$$

The Euler-Cromer Method has the second-order of approximation apropos the integration step $\Delta t$, i.e. $O\left(\Delta t^{2}\right)$.

According to the information, the system friction is neglected, indicating a significant difference in the coercive power (from the collector) and free power (in the mass of nodes). The element frictional forces are included in the model. But the determining factor is the extrinsic influence of the collector and the mechanical properties of the elements. [14-16]

Algorithm (13) is easily implemented by software (Fig. 2).

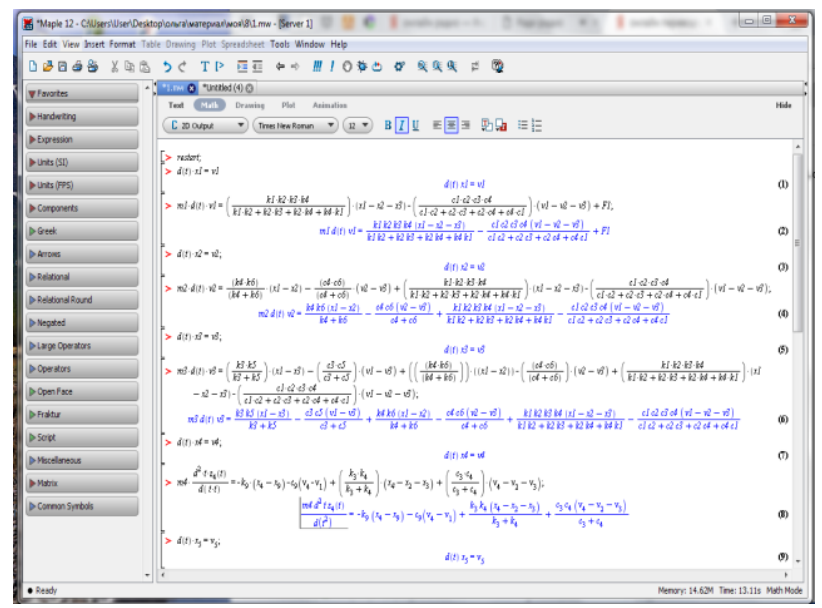

Fig. 2. Mathematical software model description.

As a result of numerous experiments, we established the correlation presence between the operating time of the collector node $y$ and the beating of the collector $x$ :

$$
(y-\bar{y})=r \frac{\sigma_{y}}{\sigma_{x}}(x-\bar{x})
$$

where $\bar{y}, \bar{x}$ - are arithmetic average values of the parameters of the beating and the operating time of the collector node; $\sigma_{\mathrm{x}}, \sigma_{\mathrm{y}}$ are standard parameter deviations of the beating and the operating time of the collector node; $r$ is the correlation coefficient.

The specified parameters and deviations are determined by the formulas:

$$
\begin{aligned}
\bar{x} & =A_{x}+h_{x} \frac{\sum m_{x} \Delta x}{N} \\
\bar{y} & =A_{y}+h_{y} \frac{\sum m_{y} \Delta y}{N} \\
\sigma_{x} & =\left[\frac{\sum m_{x} \Delta x^{2}}{N}-\left(\frac{\sum m_{x} \Delta x}{N}\right)^{2}\right] h_{x} \\
\sigma_{y} & =\left[\frac{\sum m_{y} \Delta y^{2}}{N}-\left(\frac{\sum m_{y} \Delta y}{N}\right)^{2}\right] h_{y}
\end{aligned}
$$

where $\Delta x, \Delta y$ are the reduced beating values of the collector and its operating time; $A_{x}, A_{y}$ are beating and operating time values, having the highest failure rate; $h_{x}$, $h_{y}$ are values of time intervals for measuring parameters of beating and operating time.

The values of $\Delta x, \Delta y$ are calculated by the formulas:

$$
\Delta x=\left(x-A_{\mathrm{x}}\right) / h_{\mathrm{x}}, \Delta y=\left(y-A_{y}\right) / h_{y}
$$

The correlation coefficient $r$ between the parameters $x$ and $y$ is determined from the expression

$$
r=\frac{\sum m_{x y} \Delta x \Delta y-\frac{\sum m_{x} \Delta x \sum m_{y} \Delta y}{N}}{N \sigma_{x}^{1} \sigma_{y}^{1}}
$$

As a result of calculations using formulas (18) - (22), we obtain a different type of expression (19):

$$
Y=B+k x
$$

where $B$ and $k$ are the constants for a particular type of reservoir.

If we substitute the maximum allowable value of the beating in expression (23), then we obtain the average time o failure of the collector node.

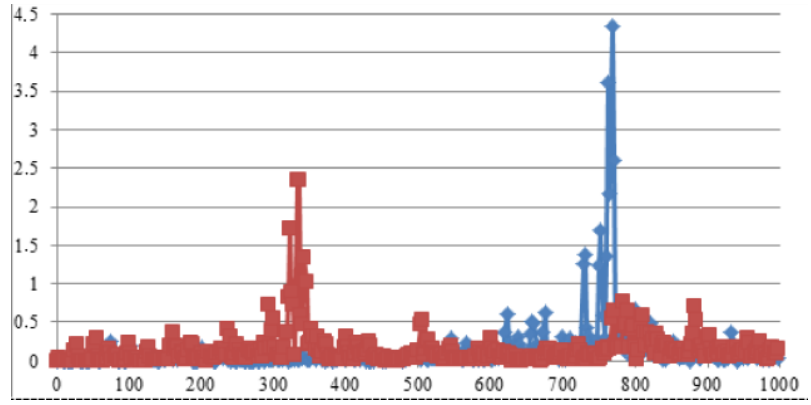

Fig. 3. Diagram of the vibration spectrum with the specified bearing defects (red) and brush-collector node (blue).

We can imagine from this diagram (Fig. 3) the expansion in a Fourier series on the interval $(-\mathrm{T} ; \mathrm{T})$ in the range $[0 ; 1000]$ has the form:

$$
f(x)=\frac{a_{0}}{2}+\sum a_{n} \cdot \cos \left(\frac{\pi \cdot n \cdot x}{T}\right)+b_{n} \cdot \sin \left(\frac{\pi \cdot n \cdot x}{T}\right)
$$


Table 1. Model of motor diagnostics.

\begin{tabular}{|c|c|c|c|c|c|c|c|}
\hline Motor characteristics & Assigned & $\begin{array}{c}\text { Measuret } \\
\text { ype }\end{array}$ & $\begin{array}{c}\text { Frequenc } \\
\mathrm{y}\end{array}$ & $\begin{array}{l}\text { Perfect } \\
\text { motor }\end{array}$ & $\begin{array}{l}\text { Diagnosed } \\
\text { motor }\end{array}$ & $\begin{array}{c}\text { Yes/N } \\
0\end{array}$ & $\begin{array}{c}\text { Defect } \\
\text { type }\end{array}$ \\
\hline Power & 10 & $\mathrm{~kW}$ & 0 & 0 & 0 & $\mathrm{NO}$ & No \\
\hline Number of collector plates & 81 & ea. & 2.5 & 0.33829 & 0.2247273 & NO & No \\
\hline Number ofbrushes & 8 & ea. & 5 & 0.43725 & 0.0082658 & $\mathrm{NO}$ & No \\
\hline Number of pairs of poles & 4 & ea. & 7.5 & 0.37799 & 0.0165316 & $\mathrm{NO}$ & No \\
\hline Power-line frequency & 50 & Hz. & 10 & 2.466 & 0.7337296 & YES & $\begin{array}{c}\text { Working } \\
\text { mode }\end{array}$ \\
\hline Working motor coefficient & 0.5 & no. & 12.5 & 0.37799 & 0.5549885 & YES & $\begin{array}{c}\text { Working } \\
\text { mode }\end{array}$ \\
\hline $\begin{array}{c}\text { Permissible wear } \\
\text { coefficient }\end{array}$ & 0.75 & no. & 15 & 5.369 & 0.0302612 & $\mathrm{NO}$ & No \\
\hline Motor speed of rotation & 900 & $\mathrm{U} / \mathrm{min}$ & 17.5 & 4.633 & 0.0055339 & NO & No \\
\hline Voltage & 220 & $\mathrm{~V}$. & 20 & 0.93433 & 0.0137296 & $\mathrm{NO}$ & No \\
\hline Number of bearings & 2 & ea. & 22.5 & 0.31815 & 0 & $\mathrm{NO}$ & No \\
\hline \multirow[t]{11}{*}{ Armature frequancy } & 30 & & 25 & 0.31815 & 0.0192635 & $\mathrm{NO}$ & No \\
\hline & & & 127.5 & 0.15879 & 0.154035 & $\mathrm{NO}$ & No \\
\hline & & & 130 & 0.05983 & 0.319621 & $\mathrm{NO}$ & No \\
\hline & & & 132.5 & 0.19906 & 1.213 & YES & Bearing \\
\hline & & & 135 & 0.25832 & 1.132 & YES & Bearing \\
\hline & & & 137.5 & 0 & 0.231001 & $\mathrm{NO}$ & No \\
\hline & & & 140 & 0 & 0.296521 & $\mathrm{NO}$ & No \\
\hline & & & 142.5 & 0.05983 & 0.635357 & YES & Bearing \\
\hline & & & 145 & 0.03969 & 0.858692 & YES & Bearing \\
\hline & & & 147.5 & 0.05983 & 0.369706 & $\mathrm{NO}$ & No \\
\hline & & & 150 & 0 & 0.219451 & $\mathrm{NO}$ & No \\
\hline
\end{tabular}

Finally, we have from the obtained data: $f(x)=317.225000000000+\sum 634.45 \cdot \cos (0.0008 \cdot \pi \cdot n \cdot x)(25)$

Using the STATISTICA software package, the curve, when applied to a diagram, proves that it is distributed according to anormal (exponential) law.

\section{Results}

Having developed a method for calculating vibrodiagnostics using the formulas, it is possible to create a model for an operated DC motor, which can evaluate the operational life of the components and the entire DC motor.

According to the DC motor data (table 1, columns 13 ), we can determine the operating parameters. Column 4 has the frequency from 0 to $1000 \mathrm{~Hz}$, which indicates the spectrum of the DC motor. Columns 5 and 6 show the spectra of an ideal (operable) and diagnosed (operated) DC motor. Then "yes/no" indicates whether there are a defect and the type of it and the degree of its development (color indicator). These data can be obtained at the diagnostics.

An additional table 2 is compiled for a more detailed analysis of the defect. It shows the wear degree of the node, its operational state and the residual resource of the nodes.
Table 2 consists of two main parts: the frequencies at which defects appear (they are separate for each DC motor); the stages of defect development are determined according to acceptable ranges (up to 0.7 - a normal stage, from 0.7 to 0.8 - acceptable wear, 0.9 - preemergency stage, and 1 - emergency mode). These stages are presented in Figure 4.

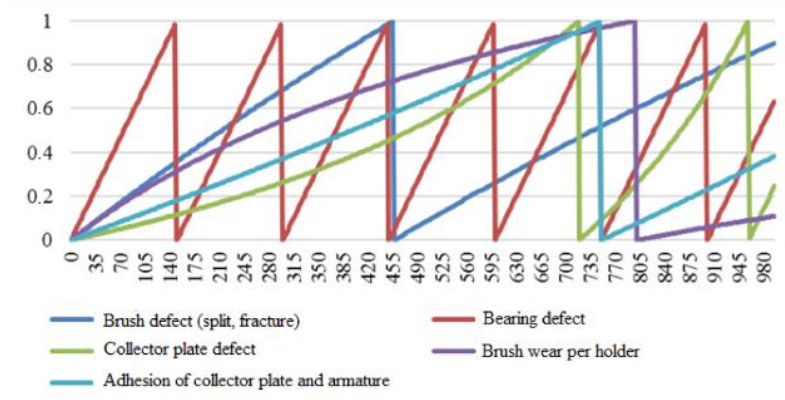

Fig. 4. Degree of development of the defect in the nodes of the electric motor.

\section{Conclusion}

Thus, this technique can prevent breakdowns and accidents on the rolling stock, save on expensive equipment and spare parts. The method of 
Table 2. Assessment of the wear degree of the motor components

\begin{tabular}{|c|c|c|c|c|c|c|c|c|c|}
\hline \multicolumn{4}{|c|}{ Defectrate } & \multicolumn{5}{|c|}{ Defect developmental stages } \\
\hline $\begin{array}{l}\text { Bearing } \\
\text { defect }\end{array}$ & $\begin{array}{l}\text { Brush } \\
\text { defect }\end{array}$ & $\begin{array}{l}\text { Brush } \\
\text { wear }\end{array}$ & $\begin{array}{c}\text { Collect } \\
\text { or } \\
\text { beating }\end{array}$ & $\begin{array}{c}\text { Collector } \\
\text { platerip }\end{array}$ & $\begin{array}{c}\text { Tobrush } \\
\text { defect } \\
\text { (split, } \\
\text { fracture) }\end{array}$ & $\begin{array}{c}\text { To } \\
\text { bearing } \\
\text { defect }\end{array}$ & $\begin{array}{c}\text { Tocollec } \\
\text { tor plate } \\
\text { defect }\end{array}$ & $\begin{array}{c}\text { Brush } \\
\text { wear } \\
\text { perholde } \\
\text { r }\end{array}$ & $\begin{array}{c}\text { To } \\
\text { adhesion } \\
\text { of col. } \\
\text { plate and } \\
\text { armature }\end{array}$ \\
\hline $\mathbf{1 0 0}$ & 400 & 400 & 2875 & 843.75 & 0 & 0 & 0 & 0 & 0 \\
\hline $\mathbf{1 0 1 . 2 5}$ & 400.31 & 401.25 & 2870 & 843.437 & 0.0062 & 0.01666 & 0.00174 & 0.00623 & 0.00296 \\
\hline $\mathbf{1 0 2 . 5}$ & 400.62 & 402.5 & 2865 & 843.125 & 0.0124 & 0.03333 & 0.00349 & 0.01242 & 0.00593 \\
\hline $\mathbf{1 0 3 . 7 5}$ & 400.93 & 403.75 & 2860 & 842.812 & 0.0187 & 0.05 & 0.00524 & 0.01857 & 0.00889 \\
\hline $\mathbf{1 0 5}$ & 401.25 & 405 & 2855 & 842.5 & 0.0249 & 0.06666 & 0.00700 & 0.02469 & 0.01186 \\
\hline $\mathbf{1 0 6 . 2 5}$ & 401.56 & 406.25 & 2850 & 842.187 & 0.0311 & 0.08333 & 0.00877 & 0.03076 & 0.01484 \\
\hline
\end{tabular}

vibrodiagnostics calculating allows going from traditional scheduled preventive repair to the repair according to the condition of the operating DC motor on the rolling stock without stopping and dismounting.

\section{References}

[1] O. Filina, Study of the service life of electric brushes of a DC motor of a rolling stock/Filina O. // News of higher educational institutions. Energy problems V. 19. № 9-10, 133-139 (2017)

[2] B.A. Khudayarov, F.Z. Turaev, Nonlinear vibrations of fluid transporting pipelines on a viscoelastic foundation Magazine of Civil Engineering, 86(2), 30-45 (2019)

[3] T.Q.T. Le, V.V. Lalin, A.A. Bratashov, Static accounting of highest modes in problems of structural dynamics, Magazine of Civil Engineering, 88(4), p. 3-13 (2019)

[4] M.F. Nizamiev, I.V. Ivshin, O.V. Vladimirov, L.V. Dolomanyk, Vibration Method for Monitoring the Technical Condition of Support-Rod Insulators Using Non-Contact Laser Vibrometry Methods, 2018 14th International Scientific-Technical Conference on Actual Problems of Electronic Instrument Engineering, APEIE 2018 - Proceedings, 8545856, 320-325 (2018)

[5] I.V. Shvetsov, Yu.V. Vankov, A.R. Zagretdinov, Control of rotary equipment unbalance with using statistical criteria comparison of vibration spectrum, IOP Conference Series: Materials Science and Engineering, 441(1),012051 (2018)

[6] O.A. Filina, A.N. Tsvetkov, Evaluation of the operational life of direct current motors, IOP Conference Series: Materials Science and Engineering, 489(1),012016 (2019)

[7] A.R. Safin, R.R. Khusnutdinov, A.M. Kopylov, The method topological optimization for design linear electric machines, 2019 International Science and Technology Conference "EastConf", EastConf 2019, 8725379 (2019)

[8] M.V. Sukhoterin, S.O. Baryshnikov, T.P. Knysh, R.A. Abdikarimov, Natural oscillations of a rectangular plates with two adjacent edges clamped, Magazine of Civil Engineering, 82(6), 81-94 (2018)

[9] M.M. Mirsaidov, R.A. Abdikarimov, N.I. Vatin, V.M. Zhgutov, D.A. Khodzhaev, B.A. Normuminov, Nonlinear parametric oscillations of viscoelastic plate of variable thickness, Magazine of Civil Engineering, 82(6), 112-126 (2018)

[10] V.P. Mushchanov, A.N. Orzhekhovskii, A.V. Zubenko, S.A. Fomenko, Refined methods for calculating and designing engineering structures, Magazine of Civil Engineering, 78(2), 101-115 (2018)

[11] R. Litvinenko, A. Aukhadeev, O. Filina, Investigation of the technical reliability of the urban electric transport system/ Transport: science, technology, management. No. 8, 60-71 (2017)

[12] Yu. Rylov, E. Stepanov, and O. Filina Study of the electric brushes of electric traction electric machines/ Scientific problems of transport of Siberia and the Far East. 437 (2012)

[13] Yu. Rylov, E. Stepanov, O. Filina, Study of the electric brushes of electric traction electric machines/ Scientific problems of transport of Siberia and the Far East 1, 320-323 (2010)

[14] A. Aukhadeev, V. Butakov, P. Pavlov, O. Filina Identification of a synergistic model of urban electric transport // Scientific problems of transport of Siberia and the Far East. 3-4, 24-27 (2017)

[15] A. Tsvetkov, N. Malev, O. Pogoditsky, M. Bolonova. Comparative analysis of the position regulators of different configurations // News of higher educational institutions. Energy problems 9-10, 116-124 (2014)

[16] Yu.N. Vershinin Electronno-teplovye i distantsionnye protsessy pri elektricheskom proboe tverdykh dielektrikov (Electronic-Thermal and Remote Processes in the Electrical Breakdown of Solid Dielectrics) (Yekaterinburg: Ural Branch, Russ. Acad. Sci.) 260 (2000) 